\title{
Research on Calculating and Analyzing the Contribution Rate of Science and Technology Progress
}

\author{
Jie LIU ${ }^{1, a,{ }^{*}}$, Ping-Ping TANG ${ }^{2, b}$, Yi-Yuan $\mathrm{HU}^{2, \mathrm{c}}$ \\ ${ }^{1}$ School of Mathematics and Computer Science, Shaanxi University of Technology, Hanzhong, \\ China, 723001 \\ ${ }^{2}$ College of Economics and Law, Shaanxi University of Technology, Hanzhong, China, 723001 \\ a slg_liujie@126.com, ${ }^{b}$ tangpingping17@163.com, ${ }^{c}$ hgt0719@snut.edu.cn \\ ${ }^{*}$ Corresponding author
}

Keywords: contribution rate; science and technology; progress; Calculate; analyze;

\begin{abstract}
Since the 1980s, the concept of the knowledge economy and the new theory of economy growth had been proposed which made the science and technology playing more important role and status on economy growth, and it get people's highest attention[1]. In this paper, the new method has been proposed and the contribution rate of science and technology progress in a city from 2004 thru 2012 has been calculated and analyzed as an example. Meanwhile, the software called Eviews has been applied to regression on the base of Solow growth model with introducing the concept of standard labor. The results showed that this method not only can calculate the contribution rate of science and technology progress but also reflect the way of economy growth in this area. Practices have proved that the proposed method in this paper is effective and reasonable relatively.
\end{abstract}

\section{Introduction}

At present, science and technology has been the principal impetus of the development of economy and society. So evaluating the impetus of economy growth quantitatively and calculating the contribution rate of science and technology progress have been the important indexes that measure the transformation of the economic growth pattern. The model which is used to calculate the progress of science and technology appeared in the 1920s, then the research literatures about the progress of science and technology and the methods of calculating have ever increased[2]. Today, there is much dispute about the theory and methods of calculating the contribution rate of science and technology progress because of that it is difficult to quantify the characteristic of this progress. In this paper, the concept of standard labor is been introduced to calculate the contribution rate of science and technology progress based on the solow growth model.

\section{Basic model}

In this paper, the solow residual method[3] is used to calculate the contribution rate of science and technology progress, the equation is expressed as follows:

$$
E=A / Y * 100 \%=1-\frac{\alpha \times K+\beta \times L}{Y} .
$$

$E$ is the contribution rate of science and technology progress. $Y$ is the average growth rate per annum of output. $A$ is the average growth rate per annum of science and technology. $K$ is the average growth rate per annum of capital. $L$ is the average growth rate per annum of labor force. $\alpha$ is the elasticity coefficient of the capital output. It means that the output will increase $\alpha \%$ when the capital increase $1 \%$ with other conditions unchanged. $\beta$ is the elasticity coefficient of the 
labor output. It means that the output will increase $\beta \%$ when the labor force increase $1 \%$ with other conditions unchanged. Usually, $\alpha$ and $\beta$ are supposed constants over a period of time, meanwhile, the sum of $\alpha$ and $\beta$ is 1 , which means that the scale effects are constant.

In this model, the capital and output are value then and the labor force is the standard labor because that the contribution rate of science and technology progress is needed to calculate every year.

\section{The determination of data index and elasticity coefficient}

\section{The Basic Data}

In this research, the basic data is chosen from statistical yearbooks of the city from 2004 thru 2012.The output is expressed as GDP and the capital is expressed as total investment in fixed assets. The values are showed as following table 1:

Table 1 The GDP and total investment in fixed assets from 2004 thru 2012 [Billion]

\begin{tabular}{cccccccccc}
\hline year & 2004 & 2005 & 2006 & 2007 & 2008 & 2009 & 2010 & 2011 & 2012 \\
\hline GDP & 192.53 & 216.58 & 246.79 & 291.21 & 352.61 & 415.64 & 509.70 & 647.48 & 772.26 \\
fixed assets & 67 & 75 & 90.66 & 120.05 & 163.63 & 238.43 & 312.80 & 348.59 & 534.86 \\
\hline
\end{tabular}

\section{The determination of Standard labor}

Because of the different quality of labor force, so working is divided to simple working and complicated working. The difference of different labor embodied in the technical content of labor although all labor can create economic output [4]. To calculate the value that is created by science and technology accurately, firstly, the GDP per capita must be calculated of the primary industry, the secondary industry and the tertiary industry.Then, the multiples of the GDP per capita should be converted based on the GDP per capita of the primary industry. At the same time, the multiples are seen as standard coefficients. Finally, the standard labor of the secondary industry and the tertiary industry are converted on the basic of the multiples mentioned in the previous step in this new method.

The standard coefficient of the secondary industry is expressed $S_{2}$. The standard coefficient of the tertiary industry is expressed $S_{3}$. The GDP per capita of the primary industry is expressed $G_{1}$. The GDP per capita of the secondary industry is expressed $G_{2}$. The GDP per capita of the tertiary industry is expressed $G_{3}$. The labor force of the primary industry is expressed $l_{l}$. The labor force of the secondary industry is expressed $l_{2}$ and the labor force of tertiary industry is expressed $l_{3}$. The standard labor of the primary industry is expressed $L_{1}$. The standard labor of the secondary industry is expressed $L_{2}$ and the standard labor of tertiary industry is expressed $L_{3}$. The calculation method is expressed as follows:

$$
\begin{aligned}
& \mathrm{S}_{2}=\mathrm{G}_{2} / \mathrm{G}_{1} . \\
& \mathrm{S}_{3}=\mathrm{G}_{3} / \mathrm{G}_{2} . \\
& \mathrm{L}_{1}=\mathrm{l}_{1} . \\
& \mathrm{L}_{2}=\mathrm{l}_{2} * \mathrm{~S}_{2} . \\
& \mathrm{L}_{3}=\mathrm{l}_{3} * \mathrm{~S}_{3} .
\end{aligned}
$$

The results are showed as following table 2 and table 3 : 
Table 2 The standard coefficient of the secondary industry and the tertiary industry

\begin{tabular}{cccccc}
\hline year & $\begin{array}{c}\text { The GDP per capita of } \\
\text { the primary industry }\end{array}$ & $\begin{array}{c}\text { The GDP per capita } \\
\text { of the secondary industry }\end{array}$ & $\begin{array}{c}\text { standard } \\
\text { coefficient }\end{array}$ & $\begin{array}{c}\text { The GDP per capita of } \\
\text { the tertiary industry }\end{array}$ & $\begin{array}{c}\text { standard } \\
\text { coefficient }\end{array}$ \\
\hline 2004 & 2856.95 & 84252.23 & 29.49 & 52531.03 & 18.39 \\
2005 & 3144.14 & 101895.11 & 32.41 & 60283.69 & 19.17 \\
2006 & 3784.00 & 119061.41 & 31.46 & 64202.80 & 16.97 \\
2007 & 4533.79 & 137850.36 & 30.41 & 75572.41 & 16.67 \\
2008 & 5856.72 & 164670.73 & 28.12 & 97765.67 & 16.69 \\
2009 & 6159.43 & 176685.98 & 28.69 & 114835.90 & 18.64 \\
2010 & 7303.82 & 222408.03 & 30.45 & 128001.28 & 17.53 \\
2011 & 9304.87 & 298638.39 & 32.09 & 145862.49 & 15.68 \\
2012 & 10514.27 & 340148.62 & 32.35 & 165469.88 & 15.74 \\
\hline
\end{tabular}

Table 3 The standard labor of the three industries [ten thousand]

\begin{tabular}{lcccc}
\hline year & $\begin{array}{c}\text { The standard labor of the primary } \\
\text { industry }\end{array}$ & $\begin{array}{c}\text { The standard labor of the } \\
\text { secondary industry }\end{array}$ & $\begin{array}{c}\text { the standard labor of } \\
\text { tertiary industry }\end{array}$ & total \\
\hline 2004 & 144.49 & 264.23 & 266.61 & 675.34 \\
2005 & 146.59 & 271.90 & 270.34 & 688.84 \\
2006 & 147.04 & 271.54 & 242.63 & 661.20 \\
2007 & 147.25 & 256.01 & 241.70 & 644.96 \\
2008 & 149.64 & 230.56 & 245.05 & 625.25 \\
2009 & 148.91 & 247.56 & 278.35 & 674.82 \\
2010 & 151.14 & 273.14 & 273.57 & 697.85 \\
2011 & 152.92 & 287.57 & 255.36 & 695.85 \\
2012 & 151.67 & 304.75 & 261.24 & 717.66 \\
\hline
\end{tabular}

\section{The determination of the elasticity coefficient}

There are three methods to determine the elasticity coefficient of the capital and labor. They are regression analysis, theoretical analysis and empiric method [5]. The regression analysis means that the least square method is used to gain the best fitting method based on the actual data. It's advantage faithful to the statistical data. The theoretical analysis does some reasonable hypothesis based on economic sense and the hypothesis is far from the actual situation usually. So the results gained are completely different. The empiric method gives the elasticity coefficient directly on the basic of empirical analysis. It is simple and popular but there is no plenty of theoretical basis. If the expected results have not been gained, the elasticity coefficient will be modified. The randomness of the contribution rate of science and technology progress will increase because of this characteristic[6,7]. The regression analysis is accepted with taking into account of every factor in this paper. The production function which is proposed by Paul H. Douglas in 1930s is expressed as following:

$$
Y=A K^{\alpha} L^{\beta}
$$

The above formula numbered 2 can be converted as follows:

$$
\ln Y=\ln A+\alpha \ln K+\beta \ln L
$$

In the process of regression, returns to scale remains unchanged .So this formula $\alpha+\beta=1$ is admissible.

According to the data in the table 1, the calculation can be gained through the formula numbered 3 by applying the software called Eviews. The results are showed as following fig. 1: 


\begin{tabular}{|c|c|c|c|c|}
\hline \multicolumn{2}{|c|}{$\square$ Equation: DITITLED } & \multicolumn{2}{|c|}{ Jorkfiles 1:=Untitled } & $\square \square$ \\
\hline \multicolumn{5}{|c|}{\begin{tabular}{|l|l|l|l|l|l|l|} 
View Proc Object Print Name Freeze Estimate Forecast Stats Resids \\
\end{tabular}} \\
\hline \multicolumn{5}{|c|}{$\begin{array}{l}\text { Dependent Variable: LOG(Y) } \\
\text { Method: Least Squares } \\
\text { Date: 09/23/13 Time: 09:59 } \\
\text { Sample: } 20042012 \\
\text { Included observations: } 9\end{array}$} \\
\hline & Coefficient & Std. Error & t-Statistic & Prob. \\
\hline $\begin{array}{c}C \\
\text { LOG(K) } \\
\text { LOG(L) }\end{array}$ & $\begin{array}{l}1.787971 \\
0.652724 \\
0.115608\end{array}$ & $\begin{array}{l}3.890466 \\
0.035253 \\
0.610662\end{array}$ & $\begin{array}{l}0.459578 \\
18.51541 \\
0.189315\end{array}$ & $\begin{array}{l}0.6620 \\
0.0000 \\
0.8561\end{array}$ \\
\hline $\begin{array}{l}\text { R-squared } \\
\text { Adjusted R-squared } \\
\text { S.E. of regression } \\
\text { Sum squared resid } \\
\text { Log likelihood } \\
\text { F-statistic } \\
\text { Prob(F-statistic) }\end{array}$ & $\begin{array}{l}0.987231 \\
0.982975 \\
0.063678 \\
0.024329 \\
13.83937 \\
231.9520 \\
0.000002\end{array}$ & $\begin{array}{l}\text { Mean depen } \\
\text { S.D. depende } \\
\text { Akaike info cr } \\
\text { Schwarz crite } \\
\text { Hannan-Quin } \\
\text { Durbin-Wats }\end{array}$ & $\begin{array}{l}\text { ent var } \\
\text { nt var } \\
\text { terion } \\
\text { ion } \\
\text { criter. } \\
\text { n stat }\end{array}$ & $\begin{array}{r}5.896912 \\
0.488034 \\
-2.408748 \\
-2.343007 \\
-2.550618 \\
2.084681\end{array}$ \\
\hline
\end{tabular}

Fig. 1 The results of linear regression

The first item of the formula numbered 3 is $\ln (A)$ that the value is 1.787971 . The two elasticity coefficients called $\alpha$ and $\beta$ are 0.652724 and 0.115608 . Furthermore, the formula numbered 3 can be expressed as follows:

$$
\ln Y=1.787971+0.652724 \ln K+0.115608 \ln L
$$

Then, the value of $\mathrm{A}$ is 5.9773 and the sum of $\alpha$ and $\beta$ is 0.7683 . Because of that the sum less than 1 , so the elasticity coefficients need to be processed by standardization method as following: $\alpha=0.652724 /(0.652724+0.115608)=0.85$

$\beta=0.115608 /(0.652724+0.115608)=0.15$

\section{The experimental results and analysis}

The results of calculation have been showed as following table 4 through applying the formula numbered 4 according to the data of table 3 .

Table 4 The contribution rate of science and technology progress in a city from 2004 thru 2012

\begin{tabular}{cccccccccc}
\hline year & 2004 & 2005 & 2006 & 2007 & 2008 & 2009 & 2010 & 2011 & 2012 \\
\hline $\begin{array}{c}\text { contribution } \\
\text { rate }\end{array}$ & $17.7 \%$ & $22.7 \%$ & $28.5 \%$ & $31.7 \%$ & $33.9 \%$ & $26.8 \%$ & $27.3 \%$ & $38.1 \%$ & $27.2 \%$ \\
\hline
\end{tabular}

The results show that the contribution rate of science and technology progress has been generally on the rise every year since 2004 except 2009 and 2012.The reason is obvious. Earthquake happened in 2008 and disaster reconstruction must been carried out from 2009, so there were fixed investments on a large scale which caused the contribution rate of science and technology progress decrease in 2009 obviously. The spur effect of disaster reconstruction began in 2010, followed by the nationwide recession. Because of the sluggish influence, the contribution rate of science and technology progress in 2012 decreased to $27.2 \%$.

\section{Conclusions and Discussion}

In this paper, a new method has been proposed to calculate the contribution rate of science and 
technology progress based on the Solow growth model and the production function which is proposed by Paul H. Douglas. In this method, the conception of the standard coefficient has been introduced with considering the difference of different labor. The results had showed that the proposed method can reflect the real situation more reasonable. Some feasible suggestion will be made in the next step to increase the contribution rate of science and technology progress. More research about building the technological innovation service system and promoting growth of science and technology should be done in future.

\section{Acknowledgement}

On the course of writing this paper till the moment of its completion, there are those who contributed to this work that I would like to express my gratefulness here. Mr. LI Peng-fei, my husband had undertaking much more homework so that I could put all my heart into composing this paper. The other one I should make a grateful acknowledgement is Mr. HU Yi-yuan, one of my teachers, who helped me a lot in translation work. In addition, thanks for the National Science Foundation to support this research.

\section{References}

[1] XU Shi-yuan,HE Kuan and FAN Zai-hu.To review the calculation of the contribution rate of science and technology progress based on solow model. Statistics and Decision. 20 14(4),9-13

[2] Capalbo SM.Measuring the components of aggregate productivity growth in US agricultural. Western Journal of agricultural Economic Review.1988,13:53 62.

[3] CHEN Zhen, CHEN Qi-qi and LI Jun.Calculation and analysis on contribution rate of agriculture science and technology progress in Henan province. Journal of Henan Agricultural University.2013,47(4),475-479

[4] CUI Xiu,JIANG Zhao-hua.The Contribution Rate of the Human Capital on China' s Economic Growth. Science of science and Management of S. \& T. 2011,32(12)168-172

[5] QI Yuan.Empirical Research on Industry Technology Progress Contribution Rate in Beijing Based on Modified Production Function.Science and Technology Management Research. 2012(24),78-83

[6] Fan S.Effects of technological change and institutional reform on production growth in Chinese agriculture.American Journal of Agricultural Economics, 1991(73):266-273.

[7] Huang Jikun,Scott Rozelle.Technological change: the recovery of the engine of productivity growth in China's rural economy. Journal of Development Economics.1996(1):337-369. 